\title{
POLA PIKIR MASYARAKAT DESA DUNGPRING DALAM MELIHAT TAYANGAN TELEVISI "BEDAH RUMAH" DI GTV: KAJIAN BUDAYA MASYARAKAT PEDESAAN
}

\author{
Tety Bekti Sulistyorini \\ Magister Pendidikan Bahasa Indonesia \\ Sekolah Pascasarjana, Universitas Muhammadiyah Surakarta \\ bektitety21@gmail.com \\ Atiqa Sabardila \\ Magister Pendidikan Bahasa Indonesia \\ Sekolah Pascasarjana, Universitas Muhammadiyah Surakarta \\ as193@ums.ac.id
}

\begin{abstract}
Abstrak
Penelitian ini bertujuan untuk mendeskripsikan (1) manfaat tayangan televisi bagi masyarakat Dusun Dungpring, Desa Ngunggahan, dan (2) pola pikir masyarakat dalam melibat tayangan televisi "Bedab Rumab" di Dusun Dungpring, Rt 03/07, Desa Ngunggahan, Kecamatan Eromoko, Kabupaten Wonogiri. Tayangan televisi memiliki pengaruh dalam perubahan pola pikir masyarakat. Jenis penelitian ini adalah kualitatif. Data penelitian ini diperoleh dari pengumpulan data secara studi lapangan dengan melakukan observasi, wawancara, angket, dan teknik dokumentasi. Buku-buku dan jurnal relevan digunakan sebagai data sekunder untuk memperkuat analisis. Data yang telah dikumpulkan dianalisis dengan menggunakan analisis deskriptif, yakni mendeskripsikan analisis secara terperinci dan sistematis. Dalam penelitian ini ditemukan babwa televisi dapat memberikan manfaat bagi masyarakat, yakni memberikan biburan dan memberikan informasi, sedangkan pola pikir masyarakat yang ditentukan oleb latar belakang profesi, usia, jenis kelamin, ekonomi, dan tingkat pendidikan menunjukkan adanya pola pikir rasa iri, rasa trenyuh, rasa bahagia, rasa malas, rasa iba, rasa gembira, dan keinginan yang kuat.
\end{abstract}

Kata Kunci: Pola pikir, Televisi, Perubahan, Masyarakat

\begin{abstract}
This study aimed to describe (1) the benefits for the community television Dungpring Rural, Ngunggahan Village, and (2) the people's mindset in watching television "Bedah Rumab" in Dungpring village Rt 03/07, Ngunggaban Village, Eromoko District, Wonogiri regency. The television show has an influence in changing the public mindset. This type of research is qualitative. This research data obtained from the field study data collection by observation, interviews, questionnaires, and technical documentation technical. Books and journals relevant to be used as secondary data to strengthen the analysis. The data collected were analyzed using descriptive analysis, which describes a detailed and systematic analysis. In the research is found that television can provide benefits to society, namely providing entertainment and providing information, the public mindset as determined by professional background, age, gender, economic, and educational levels showed the mindset of envy, a sense sank, the feeling of happiness, laziness, compassion, joy, and passion.
\end{abstract}

Keywords: Mindset, Television, Change, Society

\section{PENDAHULUAN}

Perkembangan zaman yang semakin canggih dan kehidupan masyarakat yang selalu membutuhkan berbagai informasi menjadikan media massa sebagai salah satu wujud untuk menjawab kegelisahan tersebut. Perkembangan media massa dari tahun ke tahun selalu mengalami perubahan yang signifikan. Hal ini dikarenakan adanya persaingan yang ketat antara media massa satu dengan media massa lainnya, baik media massa cetak maupun media massa elektronik. Persaingan yang sangat ketat mengakibatkan adanya kegagalan dalam penyaringan informasi sehingga informasi mentah 
yang belum layak untuk dipublikasikan menjadi informasi yang dianggap layak.

Media massa dapat diartikan juga sebagai media komunikasi dan informasi yang melakukan penyebaran informasi secara massal dan dapat diakses oleh masyarakat secara massal pula. Informasi massa adalah informasi yang diperuntukkan kepada masyarakat secara massal, bukan informasi yang hanya boleh dikonsumsi oleh pribadi (Bungin 2012).

Salah satu media massa yang muncul belakangan adalah media televisi. Media televisi keberadaanya sangat dibutuhkan masyarakat, bahkan media massa berupa radio, koran, dan sebagainya sudah sangat tertinggal jauh oleh televisi. Televisi berasal bahasa yunani yaitu tele (jauh) dan vision (melihat), jadi secara harfiah berarti "melihat jauh", karena pemirsa berada jauh dari studio tv. televisi, yang dalam bahasa Inggrisnya television, diartikan dengan melihat jauh. Melihat jauh di sini diartikan alat penangkap siaran bergambar, yang berupa audio visual dan penyiaran videonya secara broadcasting. (Zoebazary, 2010, Wahyudi, 1994, Badjuri 2010).

Berbagai tayangan televisi, mulai dari acara kartun, sinetron, kuis, acara bertajuk religi, musik, drama, news, talkshow, komedi dapat mengakibatkan adanya perubahan pola pikir pemirsa yang menyaksikannya. Faktor-faktor yang mempengaruhi pembentukan pola pikir Menurut Iskandar (2008) Terdapat 7 sumber kekuatan yang mempengaruhi proses berpikir manusia, yakni (1) Orang Tua, (2) keluarga, (3) masyarakat, (4) sekolah, (5) teman, (6) media massa, dan (7) diri sendiri. Media massa menjadi salah satu sebab perubahan pola pikir manusia karena adanya unsur pengidolaan pada suatu tontonan yang dapat menimbulkan peniruan-peniruan oleh seseorang, baik bersifat neagtif maupun peniruan yang bersifat positif.

Siaran televisi tidak serta merta dapat mempengaruhi pemirsa. Dari berbagai kajian, siaran yang dapat berpengaruh terhadap pemirsa adalah siaran yang dilakukan berulang-ulang. Perulangan yang dimaksud bisa secara utuh diulang seperti iklan, bisa pula pengulangan pesan dengan format atau adegan yang berbeda (Rakhmat, 2002)
Artikel ini bertujuan mendeskripsikan manfaat tayangan televisi bagi masyarakat Dusun Dungpring dan pola pikir masyarakat akibat melihat tayangan televisi bertajuk hadiah "Bedah Rumah" di Dusun Dungpring, Desa Ngunggahan, Kecamatan Eromoko, Kabupaten Wonogiri. Penelitian mengenai analisis televisi sudah banyak dilakukan peneliti lain, tetapi secara khusus yang membedakan penelitian ini dengan penelitian lainnya adalah objek penelitian dan perubahan pada orang yang menyaksikan televisi.

Holilah (2016) meneliti televisi dari segi dampak terhadap perilaku masyarakat. Penelitian Rizal (2016) meneliti efek menonton acara televisi terhadap sosial budaya masyarakat muslim. Penelitian Ngafifi (2014) meneliti pada aspek kemajuan teknologi da pola hidup manusia dalam perspektif sosial budaya. Ahmadi dan Nova (2007) meneliti kekerasan di televisi. C. Suprapti (2013) meneliti pengaruh tayangan televisi terhadap gaya hidup hedonis pada remaja.

Penelitian Artha (2016) meneliti pengaruh pemilihan tayangan televisi terhadap perkembangan sosial anak. Penelitian Tekkay (2017) meneliti persepsi masyarakat tentang talkshow "Mata Najwa" di metro tv. Penelitian Ma'rifah, dkk (2010) meneliti dampak menonton siaran televisi terhadap prestasi belajar siswa pada mata pelajaran Pkn. Penelitian Adi (2008) meneliti identitas kultural dan televisi lokal. Penelitian Azmi (2014) meneliti dampak media televisi terhadap prilaku sosial anak. Penelitian Susena (2015) meneliti pengaruh sinetron televisi terhadap pola hidup masyarakat pedesaan. Parma, dkk (2018) meneliti pola pikir masyarakat nelayan dalam pendidikan. Widdah (2012) meneliti pola pikir dan pendidikan. Jumiartika dan Hamzah (2015) meneliti pengaruh tayangan talkshow "sarah sehan" di net terhadap minat menonton.

Mardhani dan Poppy (2016) meneliti perilaku menonton televisi dan perkembangan anak usia sekolah menurut persepsi ibu. Parwadi (2005) meneliti pengaruh penggunaan media televisi terhadap penyimpangan nilai dan perilaku remaja berupa kekerasan, seks, dan konsumtif di kota Yogyakarta. Imra dan Dwi (2010) meneliti dampak menonton siaran televisi terhadap prestasi belajar siswa. Alfian (2014) meneliti komersialisme pada media. Herman (2008) meneliti persepsi remaja terhadap tayangan 
pornografi di televisi. Rohani (2015) meneliti pengaruh televisi terhadap aspek-aspek perkembangan anak usia 3-4 tahun. Ridwan dan Trihadi (2015) meneliti dampak sering menonton televisi pada anak usia sekolah. Salam (2016) meneliti pengaruh sinetron anak jalanan terhadap perilaku remaja di kota Samarinda. Liana, dkk (2017) meneliti pengaruh terpaan tayangan religi di televisi terhadap sikap dan perilaku takwa pemirsa.

\section{METODE}

Penelitian ini merupakan penelitian kualitatif dengan pendekatan studi lapangan. penelitian lapangan merupakan penelitian kualitatif di mana peneliti mengamati dan berpartisipasi secara langsung dalam penelitian skala sosial kecil dan mengamati budaya setempat (Kanneth, 1982). Metode Pengumpulan data pada penelitian ini terdiri atas data primer dan data sekunder. Data primer diperoleh dengan empat metode. Pertama, metode observasi, peneliti melakukan pengamatan secara langsung ke lokasi di Dusun Dungpring, Rt 03/07, Desa Ngunggahan, Kecamatan Eromoko, Kabupaten Wonogiri. Kedua, metode wawancara, pada metode ini peneliti melakukan tanya jawab secara langsung dengan masyarakat. Ketiga, metode dokumentasi, peneliti mengambil beberapa gambar sebagai bukti untuk memperkuat penelitian. Keempat, metode penyebaran angket. Penyebaran angket ini guna mengetahui tayangan televisi yang disukai oleh masyarakat setempat.

Selanjutnya, data sekunder berupa metode pustaka, peneliti menggunakan berbagai literatur berupa buku-buku, dan jurnal yang relevan untuk memperkuat penelitian. Data dianalisis menggunakan analisis dekriptif dengan mendeskripsikan hasi secara terperinci dan sistematis. Triangulasi atau keabsahan data dilakukan dengan menggunakan validasi teori dan validasi sumber.

\section{HASIL DAN PEMBAHASAN}

\section{Manfaat Televisi bagi Mayarakat Dusun Dungpring}

Media massa televisi tidak hanya memiliki dampak yang negatif, tetapi juga mampu memberikan dampak yang positif. Hal ini dikarenakan televisi mampu memberikan berbagai manfaat. Pertama, tayangan televisi mampu memberikan informasi yang dibutuhkan oleh masyarakat, terutama adalah tayangan berupa berita-berita terkait harga pangan, masalah negara, konflik antar suku, dunia politik, bencana, kecelakaan, dan informasi menarik seputar bangsa dan negara lain. Masyarakat menganggap bahwa hal ini menjadi nilai edukatif dan pengembangan wawasan masyarakat agar tidak tertinggal informasi.

Kedua, televisi mampu memberikan sarana hiburan bagi masyarakat. Masyarakat Dusun Dungpring mayoritas bekerja sebagai petani, pada musim ini petani masih menunggu memanen padi, kegiatan sehari-hari berupa aktivitas di sawah untuk melihat padi dan menjaga padi dari serangan burung. Mayoritas petani, setelah pulang dari sawah akan berkumpul dengan keluarga pada petang hari sehingga tayangan televisi mampu menciptakan rasa kebersamaan bersama keluarga. Waktu luang kebersamaan ini dimanfaatkan para petani untuk mencari hiburan agar menghilangkan penat dalam pikiran. Beberapa acara yang menghibur dan menarik menjadi daya pikat terhadap masyarakat, seperti acara komedi, acara hadiah, kuis, dan hiburan lainnya.

Bagi para pekerja buruh dan pekerja serabutan, televisi merupakan sarana untuk mencari hiburan semata, sebab setelah bekerja dalam satu hari penuh maka masyarakat memerlukan sebuah hiburan yang dapat menghilangkan rasa lelah dalam waktu sementara, yakni sebelum waktu istirahat. Bagi guru televisi adalah selingan pada saat lelah mengerjakan tugas maupun pekerjaan dari sekolah, beberapa tayangan yang dipilih berupa tayangan yang mengandung nilai pendidikan, memperluas wawasan, dan tidak jarang pula melihat tayangan televisi yang bersifat hiburan. Apabila dilihat dari beberapa persepsi masyarakat terhadap tayangan televisi, maka dapat dikatakan bahwa tayangan televisi yang bersifat memberikan hiburan, memberikan wawasan terkait perkembangan bangsa, dan nilai-nilai pendidikan dapat memberikan manfaat kepada masyarakat secara umum.

\section{Pola Pikir Masyarakat}

Hasil pengamatan dan wawancara yang dilakukan secara langsung oleh peneliti di Dusun Dungpring, Rt 03/07 Desa Ngunggahan 
Tety Bekti Sulistyorini dan Atiqa Sabardila:Pola Pikir Masyarakat Desa...

Kecamatan Eromoko Kabupaten Wonogiri. Peneliti memperoleh data bahwa Dusun Dungpring merupakan sebuah Dusun yang terletak di Desa Ngunggahan dengan 36 Kepala Keluarga (KK).

Tabel 1. Jumlah Penduduk Dungpring Rt 03/07

\begin{tabular}{ccc}
\hline Kepala Keluarga & $36 \mathrm{KK}$ & Prosentase \\
\hline Laki-laki & 51 Jiwa & $46 \%$ \\
\hline Perempuan & 61 Jiwa & $54 \%$ \\
\hline Total & 112 jiwa & $100 \%$ \\
\hline
\end{tabular}

Setelah peneliti melakukan pengamatan dan wawancara terkait jumlah penduduk, maka peneliti melakukan analisis terhadap latar belakang pendidikan dan profesi masyarakat. Pada tabel 1 menunjukkan bahwa dari total penduduk, maka jenis kelamin perempuan lebih banyak dibandingan jenis kelamin laki-laki.

Tabel 2. Tingkat Pendidikan Masyarakat

\begin{tabular}{ccc}
\hline $\begin{array}{c}\text { Jenjang } \\
\text { Pendidikan }\end{array}$ & Jumlah & Presentase \\
\hline Tidak Sekolah & 30 & $27 \%$ \\
\hline Masih SD & 12 & $11 \%$ \\
\hline Tamat SD & 24 & $21 \%$ \\
\hline Masih SMP & 5 & $4 \%$ \\
\hline Tamat SMP & 12 & $11 \%$ \\
\hline Masih SMA & 1 & $1 \%$ \\
\hline Tamat SMA & 21 & $19 \%$ \\
\hline Masih Kuliah & 1 & $1 \%$ \\
\hline $\begin{array}{c}\text { Tamat Kuliah/ } \\
\text { Sarjana }\end{array}$ & 6 & $5 \%$ \\
\hline Total & 112 & $100 \%$ \\
\hline
\end{tabular}

Tabel 2 menunjukkan bahwa masyarakat yang tidak berpendidikan (tidak tamat SD) jumlahnya sangat tinggi, yakni mencapai 27\%, sedangkan masyarakat yang berpendidikan tinggi hanya mencapai $5 \%$ saja. Latar belakang pendidikan inilah yang menjadikan masyuarakat Dusun Dungpring mayoritas bekerja sebagai petani dan buruh. Hampir seluruh masyarakat bekerja menjadi petani. Peneliti hanya menemukan satu pegawai negeri sipil (PNS). Kehidupan masyarakat yang mayoritas menjadi petani mengakibatkan banyak waktu luang yang dimanfaaatkan petani melihat tayangan televisi.
Tabel 3. Pernyataan responden terkait tayangan yang disukai

\begin{tabular}{|c|c|c|c|}
\hline Channel & Program & Frekuensi & Presentase \\
\hline GTV & $\begin{array}{l}\text { Bedah } \\
\text { Rumah }\end{array}$ & 11 & $37 \%$ \\
\hline GTV & $\begin{array}{c}\text { Super } \\
\text { Deal }\end{array}$ & 6 & $20 \%$ \\
\hline SCTV & $\begin{array}{l}\text { Orang } \\
\text { Ketiga }\end{array}$ & 5 & $16 \%$ \\
\hline SCTV & $\begin{array}{l}\text { Cinta } \\
\text { Suci }\end{array}$ & 3 & $10 \%$ \\
\hline Trans 7 & $\begin{array}{c}\text { On The } \\
\text { Spot }\end{array}$ & 2 & $7 \%$ \\
\hline $\begin{array}{c}\text { Metro } \\
\mathrm{Tv}\end{array}$ & $\begin{array}{l}\text { Kick } \\
\text { Andy }\end{array}$ & 2 & $7 \%$ \\
\hline Indosiar & Azab & 1 & $3 \%$ \\
\hline \multicolumn{2}{|c|}{ Total } & 30 & $100 \%$ \\
\hline
\end{tabular}

Tabel 3 menunjukkan bahwa dari 30 responden menyatakan bahwa acara televisi yang paling disukai adalah acara Bedah Rumab yang ditayangkan pada acara GTV. Data menunjukkan sebanyak 11 responden memilih acara Bedah Rumah dengan presentase $37 \%$.

\section{Hasil Wawancara}

Wawancara mendalam yang dilakukan oleh peneliti terhadap masyarakat dalam menyaksikan tayangan televisi dari segi perbedaan jenis kelamin, usia, profesi, latar belakang pendidikan, dan aktivitas keseharian. Sebanyak 30 masyarakat yang diberikan pertanyaan terkait acara yang digemari menunjukkan bahwa acara yang paling diminati adalah tayangan bertajuk hadiah, yakni Bedab Rumah. Acara yang diputar setiap hari Senin sampai dengan hari Minggu pukul 19.15 di GTV memang sebuah acara yang sangat menarik untuk ditonton oleh masyarakat sebagai hiburan.

Hasil wawancara juga didukung oleh keberadaan kuisioer melalui angket yang disebarkan pada 30 masyarakat yang dijadikan responden. Masyarakat cenderung memilih acara televisi bertajuk hadiah, yakni Bedah Rumah yang disiarkan oleh GTV. 


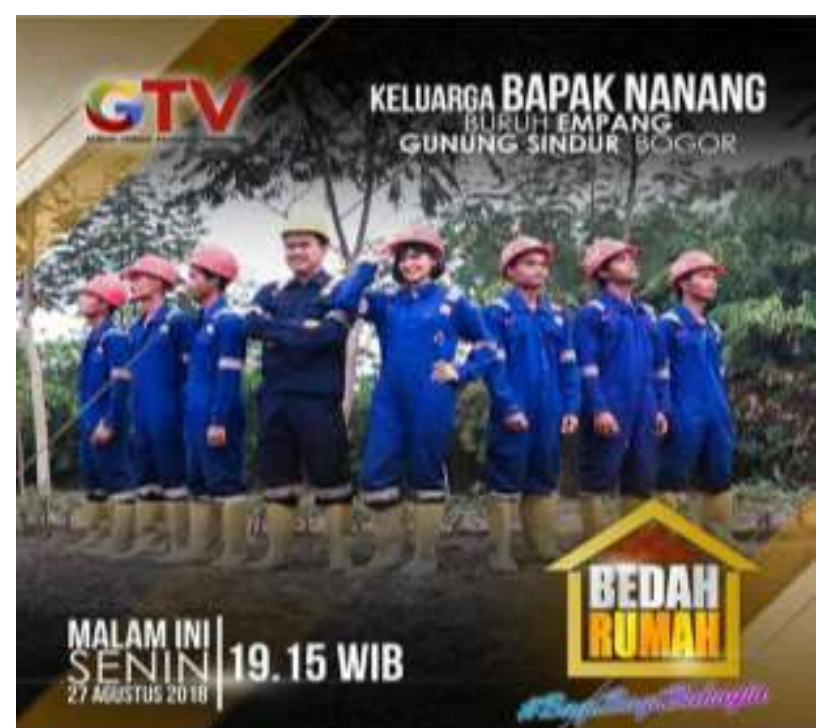

Gambar 1. Gambar Acara Bedah Rumah

\section{Berikut ini hasil wawancara dengan masyarakat.}

Narasumber : Bp. SGM (65 tahun)

Jenis Kelamin: Laki-laki

Kategori : Orang tua

Pekerjaan : Petani

".. biasane sing tak senengi acara kae tho mbak, sing omah e dibedah. Lab kae acarane apik tenan, garai aku kepingin. lab omabku urung tembok gek wes arep ambruk ngene iki. Wes koyo kandang wedhus omah e. Nak aku nonton ngono kae koyo kepingin banget mbake omabku yo didandani, entuk hadiah seko tivi. Lha piye meneh ya, ameh dandani omah ga due ragat...tayangan e kae pancen gawe aku kepingin tenan kok mbak"”

"..biasanya yang saya sukeai acara itu tho mbak, yang rumahnya dibedah. Lab itu acaranya bagus sekali, membuat saya menginginkannya. Lah rumah saya belom tembok dan sudah hampir roboh begini. Sudah seperti kandang kambing rumabnya. Kalau saya melihat seperti itu rasanya kepingin sekali mbak rumah saya di renovasi, mendapat hadiah dari televisi. Lha bagaimana ya mbak, mau memperbaiki rumah tidak ada biaya... tayangan itu memang membuat saya sangat kepingin"
Data dari narasumber tersebut dapat dianalisis bahwa narasumber merupakan seorang petani dengan penghasilan yang tidak menentu, kondisi rumah yang sudah tidak layak huni, dan kekuranga biaya menjadikan narasumber menyukai tayangan televisi yang bertajuk hadiah, sehingga pola pikir yang ada di pikiran narasumber adalah sebuah keinginan yang kuat agar bisa mendapatkan hadiah berupa bedah rumah yang sangat bagus dari televisi tanpa ada biaya yang harus di keluarkan. Dalam hal ini tayangan bedah rumah memang berdampak pada rasa keinginan masyarakat lain yang menyaksikan dengan kondisi rumah yang hampir sama dengan yang ditayangkan di televisi.
Narasumber

Jenis Kelamin

Pekerjaan

Kategori
: SL (50 tahun)]

: Perempuan

: Ibu rumah tangga

: Orang Tua "aku seneng nonton bedah rumah, nik nonton ki aku pingin omabku yo dibangun, nak udan ra trocoh, omab $e$ iso apik, nik. ndelok sinetron gur garai emosi soale sinetron saiki mung koyo masalab percintaan, warisan, mutune ra apik saiki, gur tukaran rebutan warisan marai emosi..."

"saya suka menonton bedah rumah, kalau menonton saya jadi menginginkan rumah saya juga dibangun kalau bujan tidak bocor, rumahnya bisa bagus, kalau melibat sinetron malah membuat emosi saja karena sinetron sekarang isinya hanya masalah percintaan, warisan, mutunya tidak bagus sekarang itu, hanya berantem memperebutkan warisan bikin emosi...”

Pola pikir masyarakat dalam menyaksikan tayangan televisi bertajuk pemberian hadiah secara cuma-cuma, apalalagi berkaitan ddengan hadiah rumah baru merupakan sebuah tayangan yang mampu merubah pola pikir masyarakat untuk mengubah kehidupannya. Memiliki rumah yang nyaman dan bagus menjadi pilihannya. Namun, kondisi yang tidak memungkinkan hanya mengakibatkan masyarakat secara terus menerus berkeinginan, di dalam pemikirannya bagaimana caranya agar rumahnya menjadi bagus seperti yang ditayangkan melalui televisi. $\mathrm{Hal}$ ini 
Tety Bekti Sulistyorini dan Atiqa Sabardila:Pola Pikir Masyarakat Desa...

menunjukkan adanya keinginan masyarakat yang kuat tetapi tidak disertai dengan usaha keras sehingga pola pikir yang tertanam adalah tanpa bekerja keras dan bermalas-malasan maka akan memeproleh apa yang diinginkan.

$\begin{array}{ll}\text { Narasumber } & \text { : STR } \\ \text { Jenis Kelamin } & \text { : Perempuan } \\ \text { Pekerjaan } & \text { : Pedagang }\end{array}$

".... kae lho mbak nak nonton bedah rumah ki aku seneng banget, yuh geg mesakne lho jebul isih akeh sing omah e ora layah buni, geg arep ambruk, membres, ra kepenak ngono ketoke disawang, aku pancen mikir e walah opo yo uwong sing perjuangan urip e ngono kui gek rejekine wes pancen di atur yo mbak, lha gek. wong e urip e rekoso, banjur ntuk omah apik ngono kui lak aku sing nonton melu bungah banget yo..."

"... itu tho mbak kalau melihat bedah rumah itu saya senang sekali, yubhb kasiban sekali lho ternyata masih banyak rumah yang tidak layak buni, terus bampir roboh, berantakan, tidak enak. dipandang, saya memang berpikir apakah orang-orang yang memiliki perjuangan bidupnya seperti itu rezekinya sudah diatur ya mbak, lha orang hidupnya sangat kesulitan lanjut dapat rumah bagus pasti kan saya yang melihat ikut sangat gembira ya.."

Pola pikir masyarakat yang memiliki penghasilan harian sudah pasti dan sudah memiliki rumah layak huni ternyata ikut merasakan gembira, sebab di dalam pemikirannya orang-orang yang berjuang melawan kerasnya hidup, orang yang masih bersyukur, dan masih menerima segala apa yang dimiliki akan berujung pada manisnya kehisupan, yakni memperoleh rezeki dari sumber manapun, temasuk memperoleh hadiah bedah rumah dari televisi. Hal ini menunjukkan adanya pola pikir yang nyata dan tidak ada rasa iri hati.

Narasumber : SRD (55 tahun)

Jenis Kelamin : Laki-laki

Pekerjaan : PNS (Guru)
".. acara bedah rumah itu pancen apik. mbak, jadi begini, ketika acara-acara yang lain banya bertujuan untuk gosip kehidupan rumah tangga para selebriti, tapi acara bedah rumah iki pancen apik. soal e aku mikir e ngene mbak, ndah seneng e wong-wong sing ga duwe wong sing rekoso uripe golek pangan wae angel opo meneh ndandani omah, yo to. lah nak aku pribadi yo sampek mikirku trenyuh lan bungah mbak. Iha kepiye ra trenyuh gek nak omah e wes dadi terus tiraine dibuka kae sing omah e didaandani langsung nangis bersyukur seneng kok mbak,. dadi acarane kigarai aku bersyukur mergo saya masib bidup berkecukupan dan punya rumah layak lab kok isib akeh sing uripe pancen rekoso banget..."

"..acara bedah rumah itu memng sangat bagus mbak. Jadi begini, ketika acaraacara yang lain banya bertujuan untuk bergosip tentang kebidupan rumah tangga para selebriti, tetapi acara bedah rumah ini memang bagus sekali karena saya berpikirnya begini mbak, betapa senangnya orang-orang yang tidak punya (bidup tidak berkecukupan) yang bidupnya sulit mencari makan saja susah apalagi memperbaiki rumah, iya kan. ah kalan saya pribadi ya sampai berpikir saya jadi trenyub dan bahagia mbak. Lha bagaiamana tidak trenyuh ketika rumabnya sudah selsesai direnovasi dan tirainya dibuka yang punya rumah langsung menangis beryukur bahagia kok mbak. Jadi acaranya itu membuat saya bersyukur karena saya masib bidup berkecukupan dan punya rumah yang layak untuk dibuni lah ternyata masib banyak yang hisupnya sangat sulit..."

Jawaban yang diutarakan oleh narasumber sebagai seorang guru ternyata pola pikirnya berbeda dibandingkan dengan seorang yang bekerja sebagai petani dan buruh. Hal ini tampak pada pola pikir seorang narasumber yang menjadi seorang guru dengan menyatakan adanya rasa syukur terhadap kehidupannya yang sudah berkecukupan dan memiliki hunian layak 
sehingga timbulah rasa iba dan trenyuh dalam hati narasumber. Rasa iba dan trenyuh tentu dapat dilihat dari reaksi orang yang rumahnya berhasi direnovasi dari yang sebelumnya tidak layak huni, berantakan, dan kumuh menjadi rumah yang sangat bagus, layak huni, bersih, rapi dan ditunjukkan dengan adanya tetesan air mata serta sujud syukur dari pemiliki rumah. Betapa sebuah perjuangan akan mendapatkan hasil yang begitu luar biasa.

\section{PENUTUP}

\section{Simpulan}

Masyarakat Dusun Dungpring, Rt 03/07,

Desa Ngunggahan, Kecamatan Eromoko, Kabupaten Wonogiri merupakan sebuah Dusun yang mayoritas penduduknya bekerja sebagai petani, buruh, dan pekerja serabutan. Aktivitas para petani sejak pagi hingga petang berada di sawah untuk menunggu padinya sebelum dipanen agar tidak dimakan burung. Lelah beraktivitas dalam sehari dan kejenuhan yang dirasakan menyebabkan masyarakat mencari-cari hiburan. Hiburan yang digemari adalah menyaksikan tayangan televisi menarik. Bagi masyarakat televisi sangat bermanfaat karena dapat memberikan hiburan dan memberi informasi.

Pola pikir masyarakat ketika melihat tayangan televisi bertajuk hadiah sangat beragam, hal ini dipengaruhi oleh adanya faktor umur, jenis kelamin, dan profesi. Masyarakat yang berprofesi sebagai petani dengan pendapatan pas-pasan akan merasa iri dan berkeinginan keras agar memperolehnya tanpa adanya usaha yang cukup, sehingga pola pikir malas dengan semboyan "jika rezeki tidak akan kemana” sudah menjamur dalam otak masyarakat. Bagi pedagang dalam kesehaiannya memeroleh pendapatan yang lebih dari cukup maka menganggap bahwa tayangan tersebut menghantarkannya ada pemikiran yang positif, yakni pada hal-hal yang dirasa membahagiakan, sedangkan bagi guru dengan kehidupan yang lebih dari cukup menganggap bahwa tayangan tersebut telah mengantarkan pemikirannya untuk tetap berfikir positif terhadap apa yang dilihat, mengajarkan tentang rasa syukur dan trenyuh terhadap sesama.

\section{Saran}

Saran yang dapat penulis sampaikan adalah masyarakat Dusun Dungpring, Rt 03/07, Desa Ngunggahan, Kecamatan Eromoko,
Kabupaten Wonogiri harus dapat mengubah pola pikirnya terkait dengan tayangan televisi bertajuk hadiah "Bedah Rumah" sebab sebagai pemirsa tentu tidak tahu apa yang sebenarnya terjadi di balik kayar televisi yang diolah dan ditampilkan dengan sedemikian hingga dapat merusak pola pikirnya. Budaya melihat televisi oleh masyarakat seharusnya dibatasi dengan pengetahuan dari manfaat adanya tayangan televisi sehingga masyarakat tidak terbawa arus negatif.

\section{DAFTAR PUSTAKA}

Adi, Tri Nugroho. (2008). Identitas Kultural dan Televisi Lokal. Jurnal Acta Diurna, 5(2), 96-107.

Ahmadi, Dadi \& Nova Yohana. (2007). Kekerasan di Televisi. Mediator: Jurnal Komunikasi, 8(1), 91-101.

Alfian, Muhammad Ivan. (2014). Dakwahtainment: antara Komersialisasi Media di Balik Ayat Tuhan. Jurnal Komunikasi Penyiaran Islam, 2(1), 133-148.

Artha, Dewi Juni. (2016). Pengaruh Pemilihan Tayangan Televisi terhadap Perkembangan Sosialisasi Anak. Jurnal Edu Tech, 2(1), 18-26.

Azmi, Nurul. (2014). Dampak Media Televisi terhadap Prilaku Sosial Anak. Scientiae Educatia, 3(2), 11-28.

Badjuri, Adi. (2010). Jurnalistik Televisi. Yogyakarta: Graha Ilmu.

Bungin, B. (2006). Sosiologi Komunikasi. Jakarta: Kharisma Putra Utama.

Bungin, M. Burhan. (2006). Sosiologi Komunikasi : Teori, Paradigma dan Diskursus Teknologi Komunikasi di Masyarakat. Jakarta : Kencana.

C. Suprapti Dwi Takariani. (2013). Pengaruh Sinetron Remaja di Televisi Swasta terhadap Sikap Mengenai Gaya Hidup Hedonis. Jurnal Penelitian Komunikasi Balai pengkajian dan Pengembangan Komunikasi dan Informatika (BPPKI), 16 (1), ISSN 14108291. 
Tety Bekti Sulistyorini dan Atiqa Sabardila:Pola Pikir Masyarakat Desa...

Herman, Achmad. (2008). Persepsi Remaja terhadap Tayangan Pornografi di Televisi: Studi di Tiga Sekolah Menengah Atas di Kota Palu, Provinsi Sulawesi Selatan. Jurnal Ilmu Komunikasi, 6(2), 121-130.

Holilah Ilah. (2016). Dampak Media terhadap Perilaku Masyarakat. Jurnal Studi Gender dan Anak, 3(1), 103-114.

Imra, Jayarani dan Dwi Septiwiharti. (2010). Dampak Menonton Televisi terhadap Prestasi Belajar Siswa pada Mata Pelajaran PKn di Kelas IV SD Negeri 1 Posona Kecamatan Kasimbar. Jurnal Kreatif Tadulako, 2(4), 101-114.

Iskandar. (2008). Metodologi Penelitian Pendidikan Dan Sosial (Kualitatif Dan Kuantitatif). Jakarta: Gaung Persada Press.

J. B. Wahyudi. (1994). Dasar-Dasar Manajemen Penyiaran. Jakarta: Gramedia.

Jumiartika, Vemi dan Hamzah Palalloi. (2015). Pengaruh Tayanagn Talkshow Sarah Sehan di Net. TV terhadap Minat Menonton: Studi pada Mahasiswa Psikologi UNJ Angkatan 2013. Promedia, 1(2), 1-20.

Kanneth, D. Bailey. (1982). Methods of Social Research. New York: A Division of Macmillan Publishing.

Liana, Chendi, Herta Armianti, dan M Ali. (2017). Pengaruh Terpaan Tayangan Religi di Televisi terhadap Sikap dan Perilaku Taqwa Pemirsa. Jurnal Dakwah dan Komunikasi, 2(1), 1-19.

Ma'arifah, Yusdin Gagaramusu, dan Imran. (2010). Dampak Menonton Siaran Televisi terhadap Prestasi Belajar Siswa pada Mata Pelajaran Pkn di Kelas IV SD Inpres 2 Tada Kecamatan Tinombo Selatan. Jurnal Kreatif Online Tadulako, 1(1), 89-102.

Mardhani, Vera dan Poppy Fitriyani. (2016). Perilaku Menonton Televisi dan Perkembangan Anak Usia Sekolah menurut Persepsi Ibu. Jurnal Keperawatan, 8(1), 14-19.

Ngafifi, Muhamad. (2014). Kemajuan Teknologi dan Pola Hidup Manusia dalam Perspektif Sosial Budaya. Jurnal Pembangunan
Pendidikan: Fondasi dan Aplikasi, 2(1), 3347.

Parma, H Jamaluddin Hos, dan Sarpin. (2018). Perubahan Pola Pikir Masyarakat Nelayan terhadap Pendidikan. Jurnal Neo Societal, 3(2), 416-424.

Parwadi. (2005). Pengaruh Penggunaan Media Televisi terhadap Penyimpangan Nilai dan Perilaku Remaja Berupa Kekerasan, Seks, dan Konsumtif di Kota Yogyakarta. Jurnal Sosiobumaniora, 7(1), 35-50.

Rakhmat, Jalaluddin. (2002). Psikologi Komunikasi. Bandung: Rosda Karya.

Ridwan, Ach dan Trihadi Prasetya. (2015). Dampak Sering Menonton Televisi pada Anak Usia Sekolah. Jurnal AKP, 6(1), 4146.

Rizal, Fahrul. (2016). Efek Menonton Acara di Televisi terhadap Sosial Budaya Masyarakat Muslim Kota Medan. Fitrah: Jurnal Kajian Ilmu-ilmu Keislaman, 2(2), 149164.

Rohani, Gifari Annisa. (2015). Pengaruh Televisi terhadap Aspek-aspek Perkembangan Anak Usia 3-4 Tahun. Jurnal Pendidikan Anak, 4(2), 631-639.

Salam, Ahmad Muhyi. (2016). Pengaruh Sinetron Anak Jalanan terhadap Perilaku Remaja di Kota Samarinda. Lentera, 18(2), 103-129.

Tekkay, Alfrini, Meity Himpong, dan Ridwan Paputngan. (2017). Persepsi Masyarakat tentang Talkshow 'Mata Najwa' di Metro Tv (Studi pada Masyarakat Bahu Kecamatan Malalayang). e-Journal Acta Diurna, 6(2), 1-17.

Widdah, Minnah El. (2012). Pola Pikir dan Pendidikan. Jurnal Al'Ulum, 1(1), 1-6.

Zoebazary, Ilham. (2010). Kamus Istilah Televisi dan Film. Jakarta: Gramedia Pustaka Utama. 